\title{
Wayfinding em ambientes informacionais: proposta de recomendações para avaliação no contexto da encontrabilidade da informação
}

\author{
Ewerton Bezerra Siqueira de Miranda \\ Graduado em Biblioteconomia pela Universidade Federal do Rio Grande do Norte \\ E-mail: ewerton.miranda@outlook.com \\ Fernando Luiz Vechiato \\ Doutor em Ciência da Informação pela Univ. Estadual. Paulista "Júlio de Mesquita Filho"-Marília. \\ Professor do Departamento de Ciência da Informação/UFRN \\ E-mail: vechiato2008@gmail.com
}

\begin{abstract}
RESUMO
Objetiva compreender de que modo é possível avaliar a orientação espacial (wayfinding) em ambientes informacionais analógicos e digitais, favorecendo a encontrabilidade da informação disponível. Utiliza pesquisa bibliográfica e exploratória para elaboração do referencial teórico e para a proposta de recomendações para a avaliação de ambientes informacionais na perspectiva de wayfinding. Apresenta uma contextualização conceitual a respeito de wayfinding e destaca seus principais elementos, além de descrever o processo de orientação espacial em ambientes informacionais analógicos e digitais. Contextualiza a encontrabilidade da informação e cria um diálogo entre ela e wayfinding. Apresenta, por fim, recomendações de wayfinding que foram definidas com base nos autores estudados, as quais podem ser utilizadas para o projeto e para a avaliação de ambientes informacionais analógicos e digitais.
\end{abstract}

Palavras-chave: Wayfinding. Encontrabilidade da informação. Ambientes Informacionais. Arquitetura da Informação. Recomendações.

\begin{abstract}
This article aims to understand how it is possible to evaluate the wayfinding in analogical and digital information environments, favoring the findability of available information. It uses bibliographic and exploratory research to elaborate the theoretical reference and to propose guidelines for the evaluation of information environments in the wayfinding perspective. It presents a conceptual contextualization about wayfinding and highlights its main elements, besides describing the process of spatial orientation in analogical and digital information environments. Contextualizes the information findability and creates a dialog between it and wayfinding. Finally, it presents wayfinding guidelines that have been defined based on the studied authors, which can be used for the design and evaluation of analogical and digital information environments.
\end{abstract}

Keywords: Wayfinding. Information Findability. Information Environments. Information Architecture. Guidelines. 


\section{INTRODUÇÃO}

A sociedade contemporânea vivencia um contexto sociotécnico no qual a relação e a interação entre os seres humanos e as máquinas contribuem para a organização, a disseminação, a busca, a recuperação, o acesso e o uso da informação.

Todavia, em meio a grande quantidade de informações disponíveis tanto em ambientes informacionais analógicos quanto digitais, se faz necessário estudar aspectos que contribuam para que o usuário encontre a informação desejada com rapidez e eficiência, permitindo navegar em ambientes simples ou complexos, sempre tendo uma orientação espacial para não se perder.

No contexto dos estudos sobre encontrabilidade da informação, um de seus possíveis elementos estruturais encontra-se explorado de modo incipiente na área da Ciência da Informação. Tal elemento é chamado de orientação espacial ou wayfinding, um atributo de interface, inicialmente concebido na área de Urbanismo, que pode ser aplicado em qualquer ambiente informacional, seja ele analógico, como bibliotecas e centros de documentação, ou digital, como web sites, bibliotecas digitais, repositórios digitais entre outros.

Para Ribeiro (2009), wayfinding está relacionado ao comportamento humano em saber onde está, para onde ir, escolher a melhor rota para o seu destino, reconhecer o local de destino assim que chega nele e ser capaz de inverter o processo e encontrar o caminho de volta. Wayfinding, portanto, é um elemento importante em ambientes informacionais, visto que facilita a navegação e, consequentemente, a encontrabilidade da informação.

A partir desta premissa, tem-se como questionamento: como avaliar wayfinding em ambientes informacionais analógicos e digitais? Com base neste questionamento, foram estudados aspectos teóricos, por meio de pesquisa bibliográfica e exploratória, que subsidiaram a proposta de um conjunto de recomendações que podem ser utilizadas para a avaliação, bem como para o projeto da Arquitetura da Informação de ambientes informacionais.

\section{WAYFINDING}


Wayfinding é um termo presente em inúmeras áreas, responsável pelo estudo da orientação espacial do indivíduo. A orientação é algo instintivo do ser humano, nós precisamos saber onde estamos, precisamos conhecer o caminho, devemos saber que rotas escolher e como nos localizar no espaço. A orientação espacial se dá por meio da interação do indivíduo com o meio em que se locomove. Por advento de tal processo, o sujeito absorve informações do ambiente e desenvolve a chamada "tomada de decisões", posteriormente gerando um mapa mental deste ambiente. (LYNCH, 2010; BINS ELLY; SCARIOT, 2013).

O autor Kevin Lynch foi o primeiro a apresentar a ideia de wayfinding. Em seu livro "A imagem da cidade" ele descreveu os processos de desenvolvimento da "imagem", que consiste no resultado do processo de orientação espacial do indivíduo, ou seja, seu mapa mental da cidade/espaço. (RIBEIRO, 2009; LYNCH, 2010).

Lynch (2011, p. 3) estuda a legibilidade em seus aspectos visuais e a define como a "facilidade com que cada uma das partes pode ser reconhecida e organizada em um padrão coerente”. Em um estudo sobre o livro de Lynch, Saboya (2008) destaca a importância da legibilidade quando fala que "um ambiente legível oferece segurança e possibilita uma experiência urbana mais intensa, uma vez que a cidade explore seu potencial visual e expresse toda a sua complexidade".

Ao entrevistar alguns moradores de uma cidade local e pedir para que cada um deles desenhasse um mapa mental da mesma, Lynch (2011) percebeu que, apesar de alguns mapas serem únicos, outros apresentavam um padrão de estruturação. Desse modo, cinco elementos pareceram constantes, quais sejam:

- Caminhos/Vias: Ruas familiares, passagens, rotas de metrô, linhas de ônibus, conforme pode ser observado na Figura 1: 

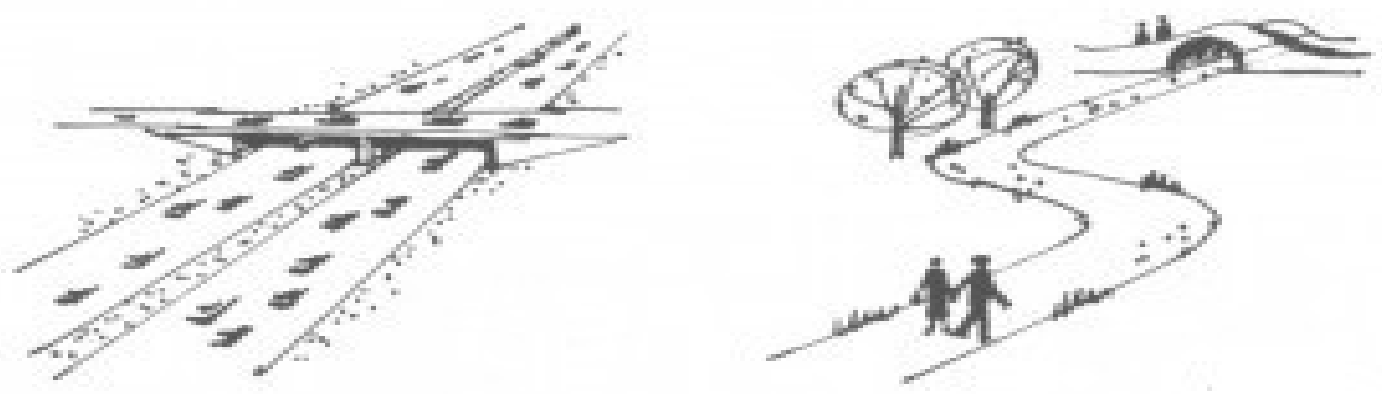

Fonte: Khan (2014)

- Limites/Bordas: As barreiras físicas de paredes, cercas, rios ou linhas costeiras, conforme pode ser observado na Figura 2:

Figura 2 - Limites/Bordas
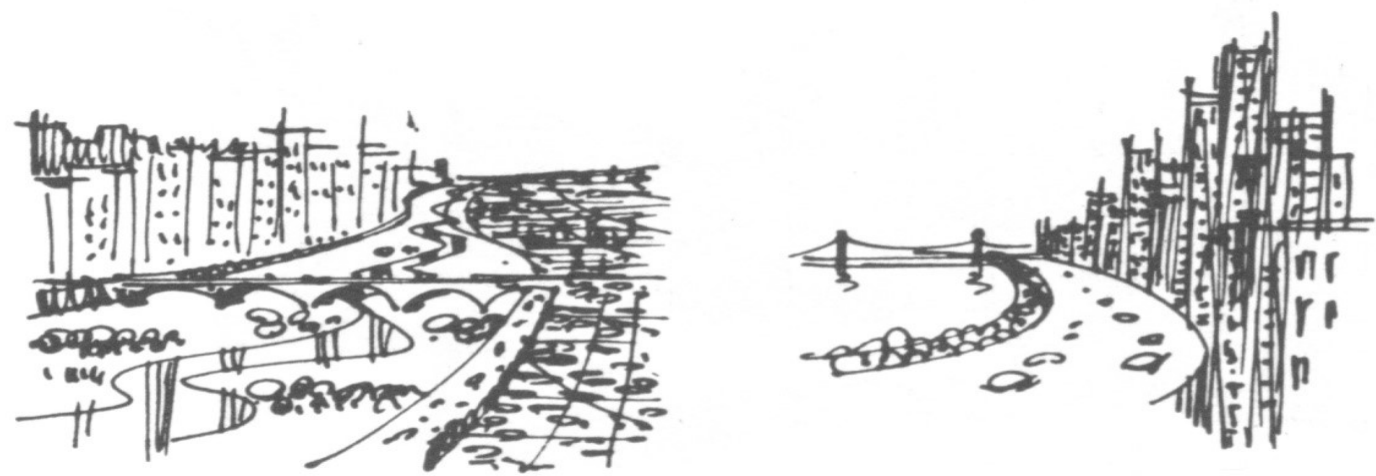

Fonte: Khan (2014)

- Bairros/Distritos: Quando falamos em bairros ou distritos, estamos falando de lugares com uma identidade distinta, como um bairro que apresenta prédios de estruturas e cores iguais, conforme apresenta a Figura 3: 
Figura 3 - Bairros/Distritos
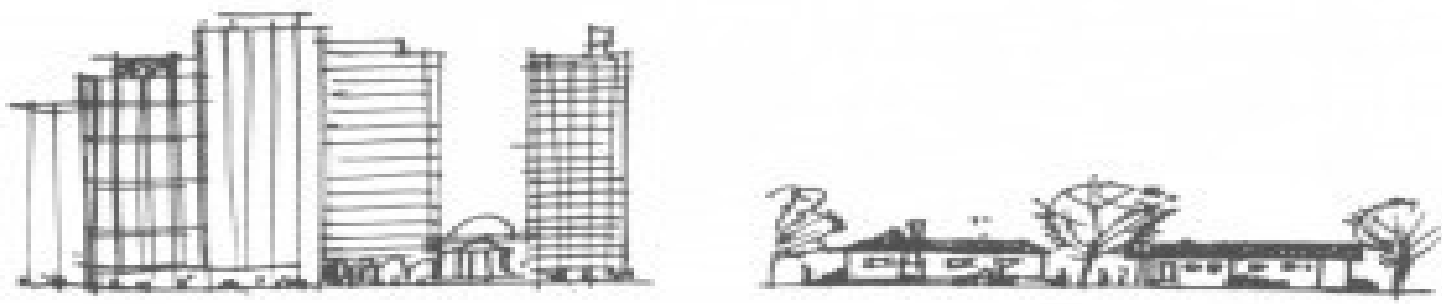

Fonte: Khan (2014)

- Pontos nodais/Nós: São os chamados "pontos de decisão" e podem ser junções, cruzamentos, bifurcações e convergências, conforme apresenta a Figura 4:

Figura 4 - Pontos nodais/Nós
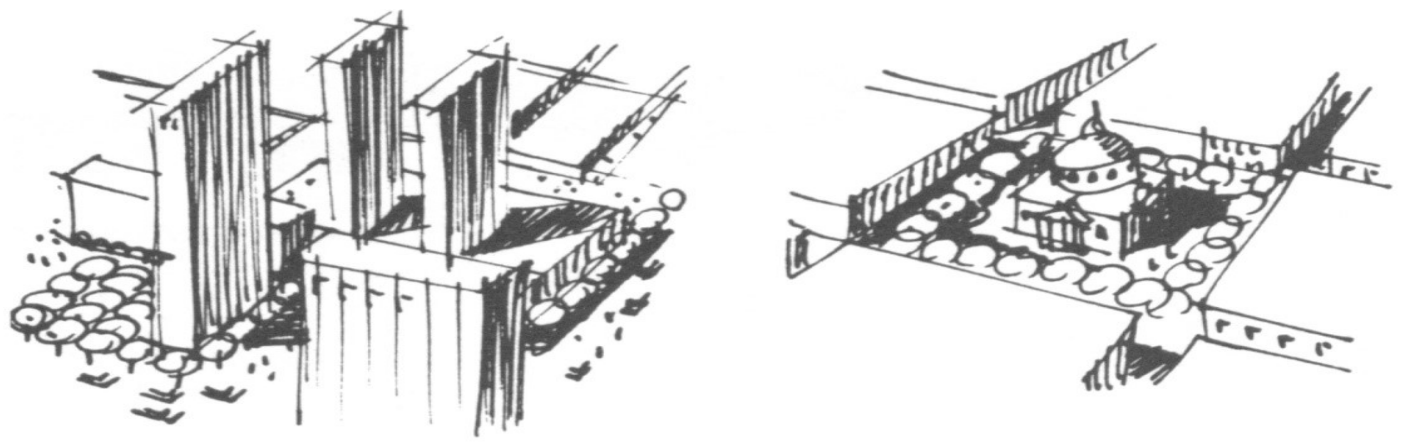

Fonte: Khan (2014)

- Marcos/Pontos de Referência: Estruturas altas e visíveis que permitem orientar-se em longas distâncias, conforme pode ser observado na Figura 5 : 

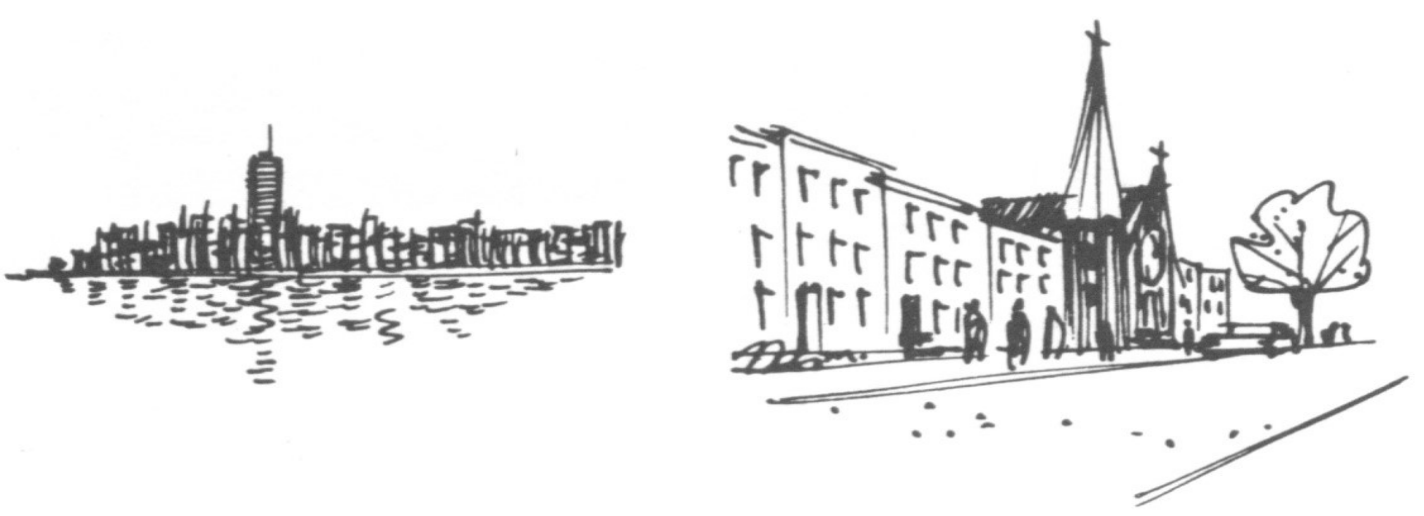

Fonte: Khan (2014)

Esses aspectos anteriormente apresentados são cruciais para a chamada "imaginabilidade" (imageability), termo usado por Lynch e descrito pelo mesmo como a:

Qualidade de um objeto físico que Ihe dá uma alta probabilidade de evocar uma imagem forte em qualquer observador. Refere-se à forma, cor ou arranjo que facilitam a formação de imagens mentais do ambiente fortemente identificadas, poderosamente estruturadas e altamente úteis. (LYNCH, 2010, p. 11)

Sendo assim, quanto mais elaborado o ambiente, mais fácil será a identificação de suas partes, proporcionando, assim, uma experiência melhor para as pessoas que transitam por ele.

O estudo de Lynch serviu de ponto de partida para vários outros pesquisadores. Com isso, em meados da década de 1970, o termo "wayfinding" passou por uma reformulação, tornando-se algo mais genérico e ganhando o sentindo de "orientação intuitiva".

Conforme descreve Ribeiro (2009, p. 28), o conceito passou a ser: “[...] baseado, então, não mais na orientação espacial, mas em uma nova noção que integrou os processos de percepção, cognitivo e de tomada de decisão necessários para encontrar o caminho".

Diante deste novo conceito, a ideia de Arthur e Passini (2002) é apresentada. Segundo esses autores, o processo de orientação espacial é feito com a realização de três etapas: a tomada de decisão, que está relacionada com a forma como o indivíduo planejará as suas ações; a execução da decisão, representada pelo processamento do plano desenvolvido na etapa anterior; por último, temos o 
processamento da informação, correspondente a percepção e processamento das mensagens enviadas do meio para o indivíduo, além do reconhecimento do mapa mental gerado pelo mesmo.

Satalich (1995) apresenta quatro componentes cruciais do wayfinding. Orientação, Decisões de rota, Mapeamento Mental e Encerramento. Para entender os quatro componentes apresentados anteriormente, Lynch e Horton (2009) explicaram os mesmos com base em perguntas: "Onde eu estou agora?", "Posso encontrar o caminho para onde quero ir?", "Minhas experiências são consistentes e compreensíveis o suficiente para saber onde estive e prever para onde devo ir em seguida?", "Posso reconhecer que cheguei ao lugar certo?".

A Figura 6 que segue apresenta um esquema representando os quatro elementos fundamentais do wayfinding:

Figura 6 - Ciclo dos quatro componentes fundamentais de wayfinding

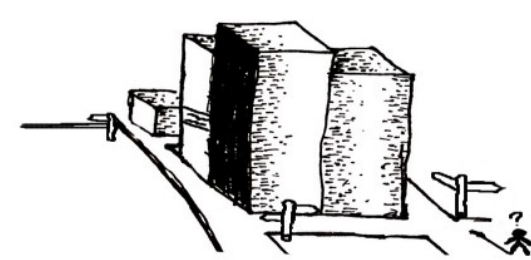

(1) riamagatio

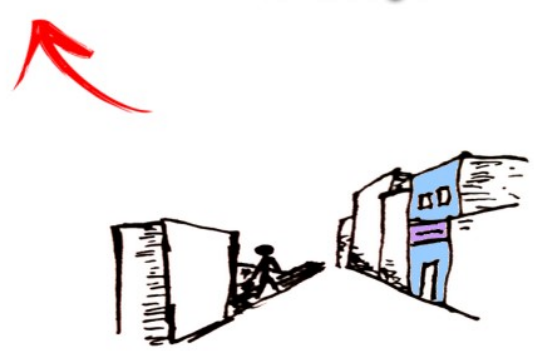

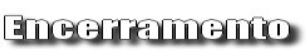

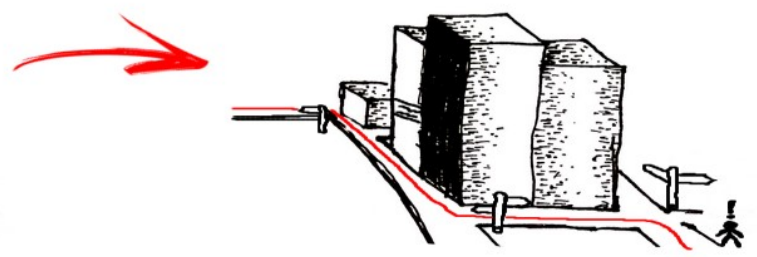

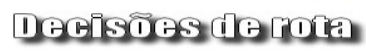

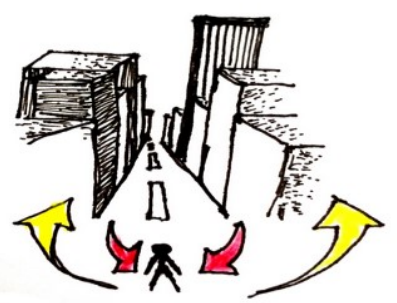

Ty

Fonte: Khan (2014)

Na prática, esse processo é descrito da seguinte forma:

[...] quando um indivíduo tenta se orientar em algum ambiente, ele explora e observa as sinalizações, rotas visíveis, consulta mapas, solicita informações a transeuntes e outras fontes de informação que estejam disponíveis. Então, ele analisa as informações recém-coletadas, gera e compara alternativas de solução para o problema, escolhe o melhor caminho e aplica esse conhecimento realizando a tarefa motora de dirigir-se ao local inicialmente 
desejado. Durante a execução da rota, provavelmente, este indivíduo estará observando os locais por onde passa, em busca de pontos de referência, ou reconsultará algum material para verificar se está no caminho certo. Ao chegar ao local, precisa compará-lo com a descrição pessoal formada a partir das informações coletadas no início de sua busca com as informações coletadas ao final do seu percurso. (PADOVANI; MOURA, 2006 apud SCARIOT, 2013).

Outra estrutura que também pode ser observada e utilizada é a apresentada por Foltz (1998), em que pontua princípios para se ter um sistema de wayfinding eficaz, sendo eles: Criação de uma identidade em cada local diferente de todos os outros; Uso de pontos de referência para fornecer pistas de orientação e locais memoráveis; Criação de caminhos bem estruturados; Criação de regiões de diferentes características visuais; Não dar ao usuário muitas opções na navegação; Utilização de pontos de vista de pesquisa; Fornecimento de sinais em pontos de decisão para auxiliar a decisão.

Wayfinding pode ser visto para uns como um processo simples e que pode ser realizado de qualquer maneira. Mas não é bem assim, tendo em vista que navegar por um ambiente mal projetado e que não fornece pistas o suficiente para as pessoas pode resultar em uma terrível experiência.

Levando em conta os conceitos abordados nesta seção, a subseção que segue tratará da aplicação do tema abordado em ambientes informacionais da Web.

\subsection{Wayfinding na navegação Web}

Ao chegarmos a esse ponto, devemos perceber as diferenças presentes entre o ambiente analógico e o digital para podermos aplicar os conceitos de wayfinding na navegação $W e b$. Ao navegarmos na $W e b$, espaços concretos e pistas de rotas não nos são apresentados, além de não haver um senso claro de direção. Sendo assim, não temos a mesma segurança de para onde ir, ao contrário do que estamos habituados no mundo físico/real. (LYNCH; HORTON, 2009). Nesse meio é necessária a criação de um espaço que utilize de todos os artifícios para manter seu usuário no caminho para chegar ao seu destino.

Tomando como fator crucial as diferenças apresentadas, devemos entender que a estrutura de um ambiente $W e b$ deve ser concreto, visível e com sinais de navegação fáceis de entender. Para relacionar o wayfinding com o ambiente Web, 
os pesquisadores Lynch e Horton (2009) criaram uma releitura dos elementos da orientação espacial de Kevin Lynch, que podem ser descritos da seguinte forma:

- Caminhos: seriam representados pela forma hierárquica comum em que a maioria dos sites é estruturada, além das trilhas de navegação, que auxiliam o usuário a se situar, conforme apresenta a Figura 7:

Figura 7 - Menu/Caminhos do website

\begin{tabular}{|c|c|c|c|c|c|c|}
\hline \multirow{3}{*}{$\begin{array}{l}\text { SciAm.com > Archaeology \& Paloontology > Dinosaurs } \\
\text { TOP|C: DinOSaurs }\end{array}$} & \multicolumn{6}{|c|}{ www.bn.com } \\
\hline & Books & DVDS & Music & Textbooks & Toys, Office, \& & More ${ }^{7}$ \\
\hline & \multicolumn{6}{|c|}{ Browse Books } \\
\hline
\end{tabular}

Fonte: Lynch e Horton (2009)

- Limites e Bairros: estes conceitos são apresentados a princípio com um pequeno problema quanto à padronização da estrutura do site. Por esse motivo, o site pareceria todo igual e o usuário não saberia ao ser movido de um ambiente para o outro. Considerando tal problema, o site deve ser flexível e apresentar uma especificidade para cada página ou seção, podendo ser utilizados sistemas de cores dentro do site, onde cada cor representa um assunto/tópico presente na sua estrutura, conforme demonstra a Figura 8:

Figura 8 - Esquema de organização por regiões.

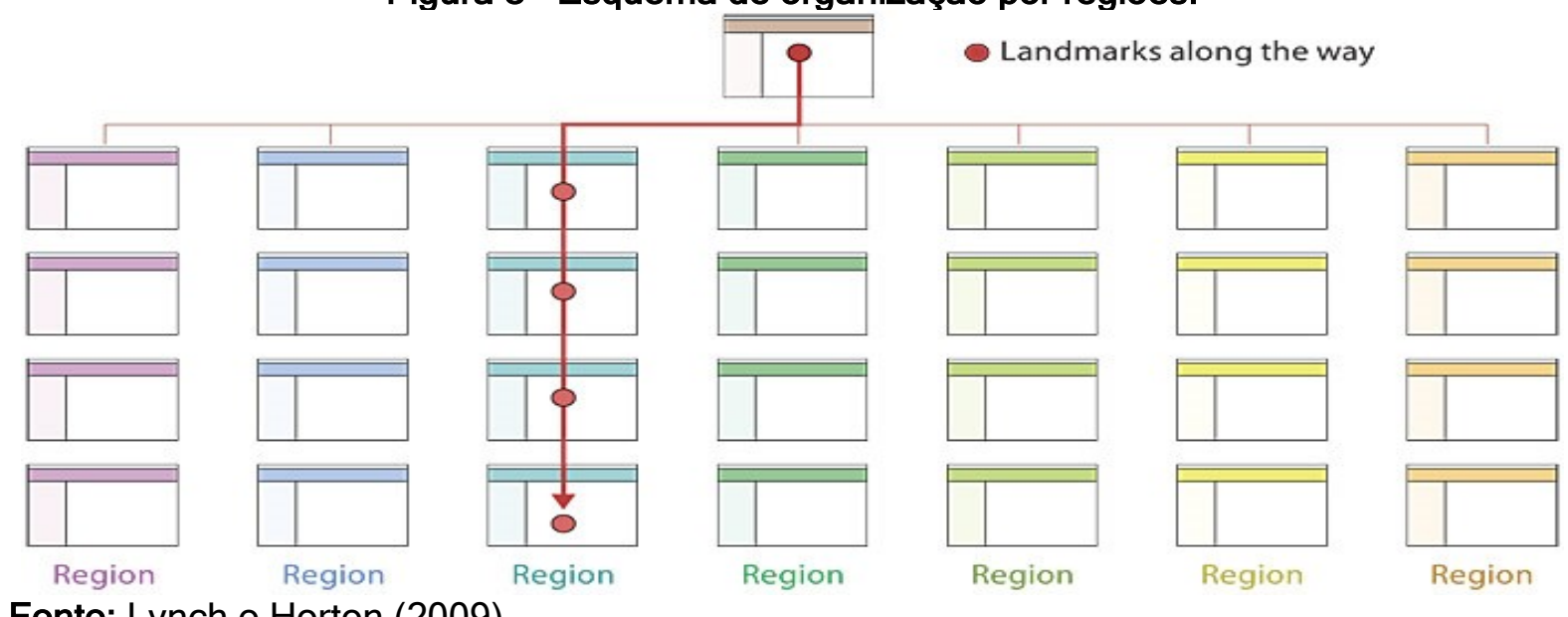

Fonte: Lynch e Horton (2009) 
- Nós: um ambiente muito sobrecarregado de informações pode acabar confundindo o usuário. Sendo assim, o layout da página principal e do menu devem ser apresentados de forma clara e objetiva, conforme demonstrado na Figura 9:

Figura 9 - Ambiente digital e real

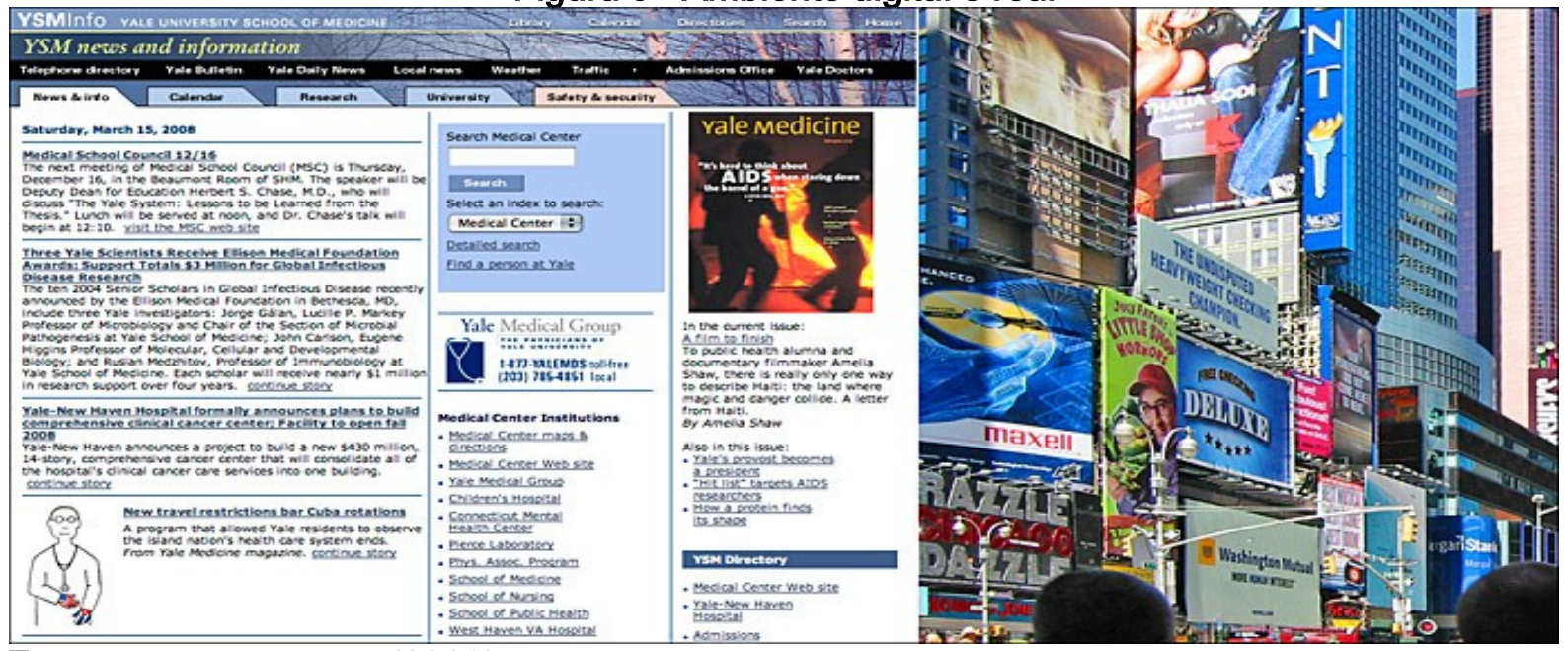

Fonte: Lynch e Horton (2009)

- Marcos: um recurso muito utilizado dentro dos sites é o sistema de busca. Apesar da eficiência de alguns, muitos usuários vão parar em um ambiente desconhecido, o que fortalece a necessidade da utilização de objetos consistentes que auxiliem o usuário a se localizar no espaço e ofereçam um ponto de referência para o mesmo. (VECHIATO; VIDOTTI, 2014; LYNCH, HORTON, 2009).

Figura 10 - Trilha de navegação.

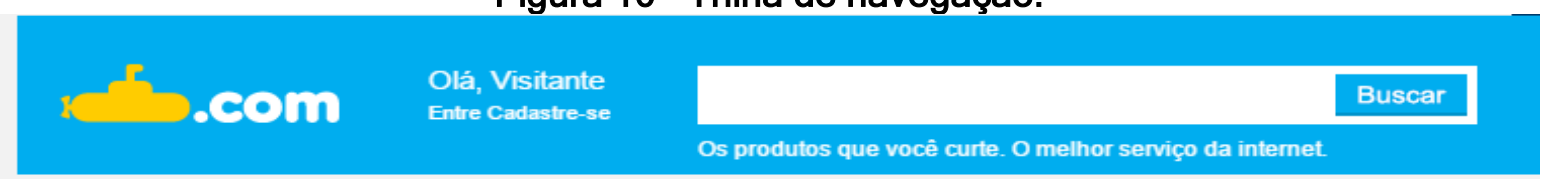

\section{를}

Livros > Literatura Estrangeira > Romances >

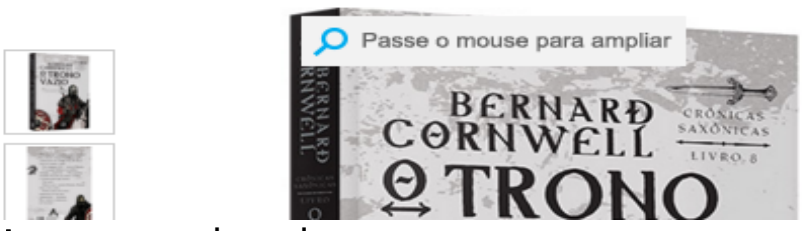

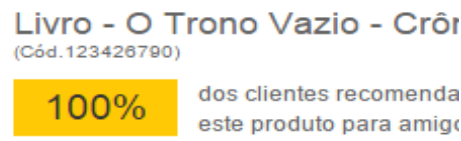

Avalie Este Produto

Fonte: <www.submarino.com> 
A estrutura de um ambiente visualmente agradável e ao mesmo tempo com usabilidade para que o usuário possa navegar sem muita dificuldade é um grande desafio, mas partindo dos conceitos aqui apresentados e relacionando-os com outras áreas, especialmente com a Ciência da Informação, pode se ter um resultado bastante agradável.

\title{
3 ENCONTRABILIDADE DA INFORMAÇÃO
}

Com o grande fluxo informacional presente nos dias de hoje, a informação precisa ser organizada e disposta de modo que facilite a sua localização. Quem nunca teve uma experiência ruim com buscas? Muitas vezes somos bombardeados com uma quantidade imensa de informações que não nos são úteis, então acabamos por desistir de encontrar o que estávamos procurando.

A ideia de que "você não pode usar o que você não pode encontrar" (MORVILLE, 2005b) serve para explicar a importância de um sistema que proporcione a encontrabilidade da informação no ambiente em que as informações estão armazenadas.

Morville (2005a) apresenta a encontrabilidade como sendo: a qualidade de um ambiente ser localizável ou navegável; o grau no qual um determinado objeto é facilmente descoberto ou localizado num ambiente; o grau no qual um sistema ou ambiente suporta a navegação e recuperação de informação. Então, devemos levar em conta que:

\begin{abstract}
Não se trata apenas de qualidade de acesso e de uso da informação ou mesmo de ambientes projetados com enfoque nas necessidades dos sujeitos. Sua perspectiva é mais ampla. Além de agregar esses objetivos, [Morville (2005)] considera que o contexto em que se inserem os sujeitos informacionais e suas características particulares interferem substancialmente na possibilidade de encontrar a informação em um determinado ambiente ou sistema de informação. (VECHIATO; VIDOTTI, 2014, p. 110).
\end{abstract}

É necessário compreender a encontrabilidade em duas partes distintas. Para isso, devemos entender que existem diferenças nos processos de encontro da informação de cada usuário. Muitas pessoas já sabem exatamente o que querem e desejam uma resposta rápida e objetiva do sistema, enquanto outros não possuem 
uma ideia clara do que querem encontrar e necessitam que os mecanismos de navegação favoreçam a descoberta de informações.

A primeira parte de usuários citados anteriormente, os que desejam informação rápida, fazem uso de buscadores, sendo muitas vezes buscadores externos aos sites como o Google. Então cabe à equipe de web design do site tornar encontrável toda a informação presente dentro dos sites, de forma que ela possa ser localizada dentro e fora dele. Para isso, sugere-se o investimento em estratégias de Search Engine Optimization (SEO). (VECHIATO; VIDOTTI 2014; MORVILLE, 2005a). As estratégias de SEO estão, em geral, associadas ao uso de metadados, ligações e recursos que facilitem a indexação das páginas disponíveis pelos robôs de busca." (VECHIATO; VIDOTTI, 2014).

Para a segunda demanda de usuários, aqueles que não têm uma ideia clara do que querem encontrar, deve-se pensar na aplicação de elementos facilitadores relacionados à estruturação e à organização das informações, pistas de navegação e uma apresentação da informação na interface que favoreça e supra as possíveis dificuldades do usuário, o que pode contribuir para a descoberta acidental de informação. (VECHIATO; VIDOTTI, 2014).

Compreendemos que várias áreas e estudos podem auxiliar no processo de desenvolvimento de um sistema que possibilite a encontrabilidade da informação. Buscando a melhoria dos mecanismos de busca e da navegação, podemos aplicar os fundamentos de wayfinding e entender como ele influencia na encontrabilidade da informação.

\section{INFLUÊNCIAS DE WAYFINDING NA ENCONTRABILIDADE DA INFORMAÇÃO}

Ao criar um diálogo sobre wayfinding e encontrabilidade da informação, podemos observar como a orientação espacial e intuitiva contribuem para a encontrabilidade da informação em ambientes analógicos e digitais. Um ambiente bem estruturado e com presença de espaços bem agrupados e diferenciados contribuem para a localização do que se quer encontrar.

No processo de busca, o usuário pode se deparar com inúmeras barreiras e desiste do que estava à procura, ou muitas vezes acabar perdido, com um sentimento angustiante e se perguntando "onde estou?", "para onde vou?" e "como retornar para onde estava?". Poucos são os que se aventuram por espaços que não 
conhecem. Isto ocorre tendo em vista que a maioria das pessoas acredita que irá se perder devido à ausência de elementos que supram a sua necessidade de se orientar no espaço.

Os conceitos de wayfinding podem ser relacionados tanto com a encontrabilidade por meio de sistema de busca, quanto por meio da navegação. Muitas vezes, ao fazer uma busca, o usuário encontra-se perdido em um ambiente que não conhece e não sabe se localizar, necessitando assim de fatores que auxiliem a sua localização, podendo ser apresentada uma trilha de navegação ou um caminho marcado/percorrido.

O conceito de encontrabilidade da informação não pode jamais ser confundido com disponibilização de informação, pois não adianta disponibilizar algo que não pode ser encontrado por todos. O seu conceito tem a ver com o ato de encontrar a informação para que ela possa ser utilizada. O wayfinding se aproxima disso, pois apresenta técnicas de sinalização e de orientação.

De acordo com Vechiato e Vidotti (2014, p. 164), "a encontrabilidade da informação sustenta-se fundamentalmente entre as funcionalidades de um ambiente informacional e as características dos sujeitos informacionais". A orientação espacial, portanto, é uma funcionalidade do ambiente que deve estar atrelada à percepção, conhecimento prévio e experiências de seus usuários.

Os referidos autores apresentam wayfinding como um dos atributos para a encontrabilidade da informação, a qual é aplicada na interface do ambiente, seja este analógico ou digital, conforme pode ser percebido na Figura 11 que segue, que apresenta o Modelo de Encontrabilidade da Informação (MEI) proposto por Vechiato e Vidotti (2014): 


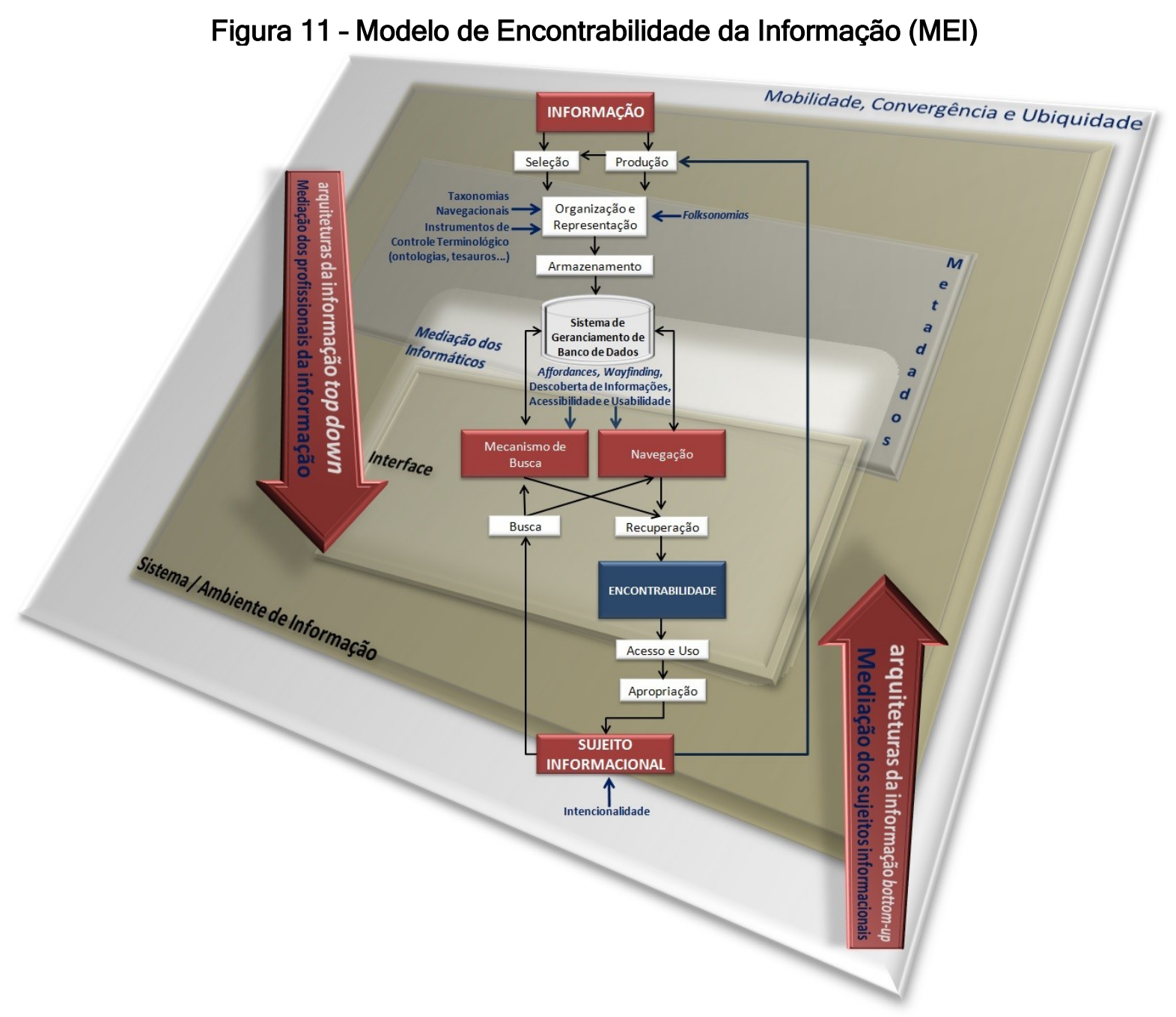

Fonte: Vechiato e Vidotti (2014, p. 172)

Percebemos que, para os autores, wayfinding está relacionada à interface do mecanismo de busca e de navegação, juntamente com outros fatores/atributos, como a descoberta de informações, a usabilidade e a acessibilidade.

Em suma, nos ambientes informacionais deve-se sempre apresentar uma estrutura simples, limpa, bem sinalizada e que evite confusões, tudo isso aliado a um leiaute visualmente agradável. Isso evitará a criação de barreiras na encontrabilidade da informação. $O$ ambiente deve sempre passar uma sensação de confiabilidade e integridade ao usuário, para que ele não duvide da qualidade do produto encontrado em sua busca. 


\section{PROPOSTA DE RECOMENDAÇÕES DE WAYFINDING PARA AVALIAÇÃO DE AMBIENTES INFORMACIONAIS ANALÓGICOS E DIGITAIS}

Para o sucesso de uma pesquisa, a escolha da metodologia se torna um ponto fundamental, pois estará ligada diretamente aos resultados gerados. Sendo assim, para esta pesquisa foram utilizados os procedimentos de pesquisa bibliográfica, que se encarrega, em um primeiro momento, da fundamentação teórica do trabalho e, em um segundo momento, da proposta de recomendações para a avaliação de ambientes informacionais analógicos e digitais.

Quando falamos de pesquisa bibliográfica "[...] é importante destacar que ela é sempre realizada para fundamentar teoricamente o objeto de estudo, contribuindo com elementos que subsidiam a análise futura dos dados obtidos." (LIMA; MIOTO, 2007, p. 44). Com isso, o trabalho objetivou estruturar e esclarecer a relação entre os conceitos de Wayfinding e Encontrabilidade da Informação, permitindo um melhor entendimento dos temas para dar continuidade à pesquisa. A pesquisa bibliográfica deu-se por meio de materiais físicos e digitais, desde livros, artigos e bases de dados nacionais e internacionais.

Além disso, foi realizada pesquisa exploratória, que tem como objetivo "[...] familiarizar-se com um assunto ainda pouco conhecido, pouco explorado. Ao final de uma pesquisa exploratória, você conhecerá mais sobre aquele assunto, e estará apto a construir hipóteses." (SANTOS, 2010, p.1).

Para elaborar recomendações específicas de wayfinding para ambientes informacionais, utilizamos a releitura dos elementos de Lynch (2010) realizada por Horton e Lynch (2009), além dos princípios do design para wayfinding apresentados por Foltz (1998).

Em um primeiro momento, serão apresentadas as recomendações propostas de wayfinding para ambientes informacionais analógicos (Quadro 1) e, em seguida, serão fornecidas algumas dicas para a estruturação de um ambiente informacional analógico, com ênfase em biblioteca, que proporcione um processo de wayfinding eficaz.

Quadro 1 - Recomendações de wayfinding para ambientes informacionais analógicos 


\section{Recomendações}

1. Disponibilizar um mapa bem estruturado do local.

2. Estruturar as rotas de forma que auxiliem a navegação e busca.

3. Oferecer sinalizações ou pistas (affordances) para auxiliar na tomada de decisão.

4. Criar uma identidade para cada espaço, diferenciando-o dos outros.

5. Fornecer características visuais distintas para cada região.

6. Fazer uso de um marco ou ponto de referência para auxiliar o usuário a situar-se no espaço.

Fonte: Autoria própria (2016), com base em Foltz (1998) e Lynch (2010)

As recomendações elaboradas serão descritas e explicadas a seguir tendo como ênfase o ambiente informacional de biblioteca.

\section{Recomendação 1 - Disponibilizar um mapa bem estruturado do local}

Levando em conta o pressuposto de que o usuário busca informações pertinentes sobre o caminho que deve seguir antes de iniciar o seu processo de encontrabilidade da informação, devemos perceber a importância da disponibilização de um mapa que demonstre que "você está aqui". O mapa deve ser bem estruturado e apresentar de forma clara e objetiva toda a estrutura do ambiente. Para que o mapa tenha sucesso em sua função é necessário que haja uma diferenciação de suas partes, em que poderá explicitar três elementos:

- Vias - referente aos caminhos da biblioteca, suas rotas principais e corredores que nos levarão aos locais desejados e pontos de decisão;

- Limites - Delimitação dos espaços da biblioteca, apresentando e diferenciando o acervo dos setores presentes na biblioteca, demonstrar até onde o usuário pode ir, sem que cometa o erro de entrar em um lugar restrito ou um caminho que tenha dificuldade de retornar;

- Distritos - estantes que podem ser relacionadas por características como tipo de suporte, assunto ou área do conhecimento (número de chamada).

O mapa de shopping representado na Figura 12 pode servir de exemplo para a elaboração de um mapa de ambientes informacionais analógicos. 
Figura 12 - Exemplo de mapa de shopping
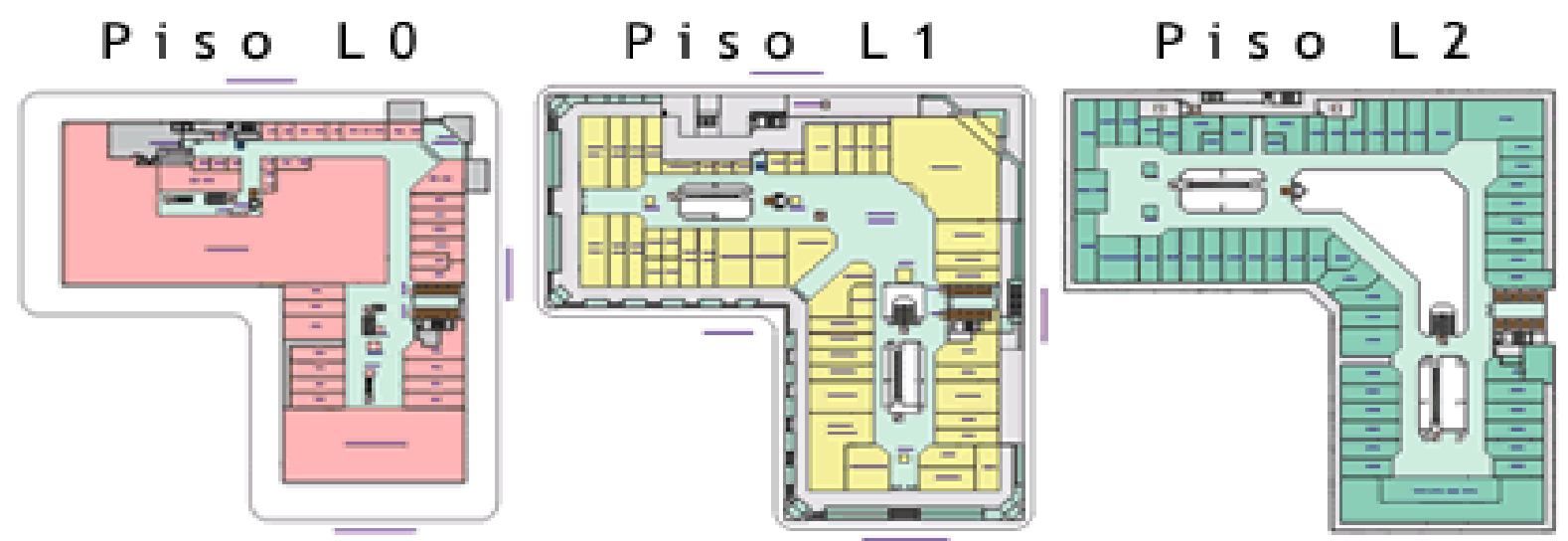

Fonte:< http://www.shoppingaldeota.com.br/mapa.asp>

Recomendação 2 - Estruturar as rotas de forma que auxiliem a navegação e busca

As rotas devem ser apresentadas de forma clara e devem dar uma visão ampla de onde ela irá nos levar, mostrando para que caminho as pessoas devem seguir. Esse é um dos fatores que contribuem para a navegação em um espaço. A rota deve apresentar o caminho de modo que não confunda o usuário.

Recomendação 3 - Oferecer sinalizações ou pistas (affordances) para auxiliar na tomada de decisão

O ambiente deve ser bem sinalizado e evitar confusões. Na estrutura de uma biblioteca de porte médio ou grande, existem vários fatores que podem dificultar a navegação no local. Elementos como a grande quantidade de estantes e de setores dentro da biblioteca acabam criando inúmeros pontos nodais, ou ponto de decisões. Este é o momento em que o usuário deve escolher o caminho para onde precisa ir, sendo assim ele necessita de um auxílio para tomar a decisão correta. Uma estrutura bem sinalizada fará com que o ambiente converse com o usuário e fará com que ele tome as decisões corretas no seu processo de encontrabilidade da informação.

Dispor estas informações para o usuário também é de extrema importância em bibliotecas de pequeno porte, pois é um dos recursos mais cruciais para ela, já 
que sua limitação de tamanho dispensa o uso de um mapa explicativo do ambiente, dependendo apenas da sinalização e dicas apresentadas pelo local.

Recomendação 4 - Criar uma identidade para cada espaço, diferenciando-o dos outros

Caracterizar e dar identidade para todo local navegável faz com que o mesmo seja mais perceptível e diferente dos outros, facilitando assim o processo de imaginabilidade. Quanto mais características um local oferecer para a sua memorização, mais fácil será lembrado no processo de criação de um mapa mental, facilitando a navegação. (FOLTZ, 1998).

\section{Recomendação 5 - Fornecer características visuais distintas para cada região}

Para auxiliar a busca informacional, um local pode ser subdivido em regiões com características próprias para auxiliar o wayfinding. Regiões são geralmente caracterizadas pelos elementos que as constituem, podendo ser por aparência física, função ou uso. Uma região deve ser visualmente diferente e deve também ser caracterizada como um limite que funcionará como um agrupador de materiais e delimitador de uma área. A divisão e agrupamento das mais distintas coleções de uma biblioteca podem ser tidos como regiões.

Recomendação 6 - Fazer uso de um marco ou ponto de referência para auxiliar o usuário a situar-se no espaço

A função dos marcos pode ser dividida em duas, sendo a primeira para a orientação espacial: ao passar por um marco a pessoa poderá utilizá-lo para saber de onde veio e onde está no momento atual, assim, situando-se no espaço. Sua segunda função diz respeito a memorização, que contribuirá para a criação de um mapa mental e será usado como referência no processo de encontrabilidade da informação.

No que se diz respeito a um ambiente informacional digital, a ideia ainda consiste em deixar o usuário sempre o mais orientado o possível. Desse modo, 
recomendações foram propostas para auxiliar na estruturação de ambientes digitais que favoreçam a encontrabilidade da informação, fazendo uso de wayfinding.

No Quadro 2 que segue são apresentadas as recomendações e os autores utilizados como referência para a elaboração das mesmas:

Quadro 2 - Recomendações de wayfinding para ambientes informacionais digitais

\begin{tabular}{|c|c|}
\hline Recomendações & Autores \\
\hline $\begin{array}{l}\text { 1. Criar um ambiente que permita a } \\
\text { encontrabilidade da informação tanto por meio } \\
\text { do mecanismo de busca como pelo sistema de } \\
\text { descoberta acidental de informação. }\end{array}$ & $\begin{array}{c}\text { Morville (2005); } \\
\text { Lynch e Horton (2009) }\end{array}$ \\
\hline $\begin{array}{l}\text { 2. Oferecer recursos que permitam que o usuário } \\
\text { situe-se no site e sempre saiba onde está } \\
\text { exatamente. }\end{array}$ & Lynch e Horton (2009) \\
\hline $\begin{array}{l}\text { 3. Apresentar um leiaute objetivo e que não } \\
\text { confunda o usuário. }\end{array}$ & Lynch e Horton (2009) \\
\hline $\begin{array}{l}\text { 4. Criar uma identidade para cada ambiente do } \\
\text { site. }\end{array}$ & Lynch e Horton (2009) \\
\hline $\begin{array}{l}\text { 5. Dispor informações para que o usuário consiga } \\
\text { saber que achou o que realmente estava } \\
\text { querendo encontrar. }\end{array}$ & $\begin{array}{c}\text { Morville (2005); } \\
\text { Lynch e Horton (2009) }\end{array}$ \\
\hline
\end{tabular}

Fonte: Autoria própria (2015)

As recomendações de wayfinding específicas para ambientes informacionais analógicos e digitais elaboradas com base nos autores citados e apresentadas nos Quadros 1 e 2 fornecem subsídios para a avalição. Desse modo, recomendações se constituem como um importante instrumento de coleta de dados para auxiliar projetistas e avaliadores.

\section{CONSIDERAÇÕES FINAIS}

Neste artigo, foi utilizada a concepção de Morville (2005) de que wayfinding é parte constituinte do processo de encontrabilidade da informação. Com auxílio dos subsídios teóricos da pesquisa, foi possível propor recomendações de wayfinding específicas para ambientes informacionais analógicos e digitais.

Vale salientar que houve dificuldades de se encontrar estudos sobre encontrabilidade da informação e Wayfinding, com ênfase na Ciência da Informação, tornando esta pesquisa pioneira a se aprofundar na união dos temas e no estabelecimento de uma relação entre eles. 
Podemos observar que os fatores que influenciam no wayfinding estão por toda parte, além de que uma boa organização e sinalização do espaço evita transtornos durante a navegação. A orientação espacial torna-se um grande aliado na busca informacional, no momento que ele torna um objeto, informação ou local mais encontrável, exercendo grande influência na jornada de um indivíduo dentro de um ambiente informacional.

Por fim, o estudo demonstra a clara relevância do wayfinding para a estruturação de locais de âmbito informacional analógico ou digital e sua influência no processo de encontrabilidade da informação.

\section{REFERÊNCIAS}

ARTHUR, P.; PASSINI, R. Wayfinding: People, Signs, and Architecture. Oakville: Focus Strategic Communications, 2002.

FOLTZ, M. A. Designing Navigable Information Spaces. 1998. 130 f. Dissertação (Mestrado) - Curso de Science, Department Of Electrical Engineering And Computer Science, Massachusetts Institute Of Technology, Cambridg, 1998. Disponível em: $<$ http://rationale.csail.mit.edu/publications/Foltz1998Designing.pdf >. Acesso em: 12 dez. 2016.

KHAN, A. The image of the city: Kevin Lynch. Qatar University. 2014. <http://blogs.qu.edu.qa/ha1003881/files/2014/03/for-more-information-click-here.pdf>. Acesso em: 12 dez. 2016.

LIMA, T. S. de; MIOTO, R. C. T. Procedimentos metodológicos na construção do conhecimento científico: a pesquisa bibliográfica. Revista Katálysis, Florianópolis, v. 10, p.37-45, mar. 2007.

LYNCH, K. A imagem da cidade. São Paulo: WMF Martins Fontes, 2010.

LYNCH, P. J.; HORTON, S. Web style guide: basic design principles for creating web sites. 3. ed. 2009. Disponível em: <http://webstyleguide.com/wsg3/>. Acesso em: 12 dez. 2016.

MORVILLE, P. Ambient findability. Sebastopol: O’Really, 2005a.

MORVILLE, P. Ambient Findability: Findability Hacks. A List Apart, 11 out. 2005b. Disponível em: <http://alistapart.com/article/ambientfindability>. Acesso em: 12 dez. 2016. 
RIBEIRO, L. G. Onde estou? Para onde vou?: ergonomia do ambiente construído: wayfinding e aeroportos. 2009. 266 f. Tese (Doutorado em Artes e Design) Pontifícia Universidade Católica do Rio de Janeiro, Rio de Janeiro, 2009. Disponível em: Acesso em: 24 ago. 2015.

SABOYA, R. Kevin Lynch e a imagem da cidade. 2008. Disponível em:

$<$ http://urbanidades.arq.br/2008/03/kevin-lynch-e-a-imagem-da-cidade/>. Acesso em: 12 dez. 2016.

SANTOS, C. J. G. dos. Tipos de Pesquisa. Disponível em:

<http://www.oficinadapesquisa.com.br/APOSTILAS/METODOL/_OF.TIPOS_PESQUI SA.PDF>. Acesso em: 12 dez. 2016.

SATALICH, G. A. Navigation and Wayfinding in Virtual Reality: Finding Proper Tools and Cues to Enhance Navigation Awareness, Master's Thesis, University of Washington, 1995. Disponível em

$<\mathrm{ftp}: / /$ hitl.washington.edu/pub/publications/satalich/th-95-4.pdf>. Acesso em: 20 ago. 2015

SCARIOT, C. A. Avaliação de sistemas de informação para wayfinding: um estudo comparativo entre academia e mercado em Curitiba. 2013. 179 f. Dissertação (Mestrado) - Curso de Design, Universidade Federal do Paraná, Curitiba, 2013. Disponível em: <http://dspace.c3sl.ufpr.br:8080/dspace/handle/1884/30375>. Acesso em: 12 dez. 2016.

VECHIATO, F. L.; VIDOTTI, S. A. B. G. Encontrabilidade da informação. São Paulo: Cultura Acadêmica, 2014. Disponível em:

<http://repositorio.unesp.br/handle/11449/126218>. Acesso em: 12 dez. 2016. 